\title{
Electrostatic Attraction
}

National Cancer Institute

\section{Source}

National Cancer Institute. Electrostatic Attraction. NCI Thesaurus. Code C73472.

The attraction between dissimilar exposed charges on two or more molecules. 